\title{
Analyses on the Optimization Routes of Jiangxi Ceramic Creative Cultural Industry
}

\author{
Xiong Wei \\ Jingdezhen Ceramic Institute 333000
}

Keywords: Jiangxi ceramic; creative cultural industry; routes

\begin{abstract}
In the context of social development, ceramic creative cultural industry is essential to promote the long-term development of Jiangxi ceramic industry. From the advantages in development of Jiangxi ceramic creative cultural industry, this paper put forward problems exit and discussed its optimization routes, namely strengthening resource management, reforming ceramic creative industry, innovating the human management mode and optimizing human resource structure. Brand effects form in converting the ceramic cultural development ideas.
\end{abstract}

\section{Advantages in the development of Jiangxi ceramic creative cultural industry}

\subsection{The rich ceramic cultural remains in Jiangxi}

The long-standing and well-established ceramic industry in Jiangxi, Jingdezhen as the representative, preserves a complete ceramic civilization system along the history of 2,000 years. It could be said that Jiangxi, along with its rich intangible cultural heritage, has an unparallel ceramic cultural remains.

From the current situation, the rich ceramic cultural remains in Jiangxi, including porcelain, coal and clay guide, blank and kiln buildings, the Old Town city government office and ferry terminals etc, a total number of 1,500 with 136 in the South River basin.

Besides, the many regulations in professional etiquette and festivals combined a comprehensive cultural heritage system. Traditional manual skills and ceramic workshops are among the first listed on the national intangible cultural heritages by the State Council.

Chart.1 Historical and cultural protection units in Jingdezhen, Jiangxi

\begin{tabular}{|c|c|c|c|c|}
\hline Number & $\begin{array}{l}\text { Name of the cultural } \\
\text { protection units }\end{array}$ & $\begin{array}{l}\text { Protection } \\
\text { level }\end{array}$ & Address & Ceramic cultural protection remains \\
\hline 1 & $\begin{array}{l}\text { Ruins Protectorate of the } \\
\text { Imperial Kiln in Ming and } \\
\text { Qing Dynasty in Mt Pearl }\end{array}$ & National & $\begin{array}{ll}\text { The } & \text { top } \\
\text { of } & \text { Mt } \\
\text { Pearl } & \end{array}$ & $\begin{array}{l}\text { Firstly discovered royal kiln remain } \\
\text { from early Ming, Xiangjinong Lane } \\
\text { Folk Houses in Ming Dynasty }\end{array}$ \\
\hline 2 & $\begin{array}{l}\text { Ruins Protectorate in } \\
\text { Hutian Kiln }\end{array}$ & National & $\begin{array}{l}\text { Hutian } \\
\text { kiln }\end{array}$ & $\begin{array}{l}\text { The typical example of folk kilns } \\
\text { ruins }\end{array}$ \\
\hline 3 & $\begin{array}{l}\text { Mt Maple Ceramic } \\
\text { Culture Expo Area }\end{array}$ & Provincial & Mt Maple & $\begin{array}{l}\text { Ancient residents and ceramics } \\
\text { construction }\end{array}$ \\
\hline 4 & $\begin{array}{l}\text { Sanlv Temple Historical } \\
\text { Reservation }\end{array}$ & Provincial & $\begin{array}{l}\text { Sanlv } \\
\text { Temple }\end{array}$ & $\begin{array}{l}\text { Sanlv Temple, Ming and Qing } \\
\text { Dynasty Street, the Ancient Wharf, } \\
\text { Yangfu Temple, Ming Residents in } \\
\text { Liujia Lane }\end{array}$ \\
\hline 5 & $\begin{array}{l}\text { Fuliang Old Town } \\
\text { Cultural Reservation }\end{array}$ & Provincial & $\begin{array}{l}\text { Fuliang } \\
\text { Old } \\
\text { Town }\end{array}$ & $\begin{array}{l}\text { Red Spire of Northern Song } \\
\text { Dynasty, County Yamen of Qing } \\
\text { Dynasty }\end{array}$ \\
\hline 6 & $\begin{array}{l}\text { China Clay } \\
\text { Reservation }\end{array}$ & National & $\begin{array}{l}\text { Kaolin } \\
\text { Porcelain } \\
\text { Clay } \\
\text { Mine }\end{array}$ & $\begin{array}{l}\text { Mine sites, ancient wharfs, } \\
\text { elutriation pits and tailing } \\
\text { embankment in three dynasties of } \\
\text { Yuan, Ming and Qing }\end{array}$ \\
\hline
\end{tabular}




\begin{tabular}{llllll}
\hline & \multicolumn{2}{l}{ Yao Li Historical Cultural } & & \\
and Economic & Tourism & National & Yao Li & $\begin{array}{l}\text { Enchanting landscape and unique } \\
\text { historical cultural attractions }\end{array}$ \\
$\begin{array}{l}\text { Reservation } \\
\text { Leping }\end{array}$ & Historic & National & Leping & Xuyan Stage \\
\hline
\end{tabular}

Several historical and cultural famous cities in Jingdezhen Jiangsu, where rich ceramic culture heritage remain, are shown in Chart.1.

In the Ruins Protectorate of the Imperial Kiln in Ming and Qing Dynasty in Mt Pearl, wares from Yongle, Xuande and Chenghua reign in Ming Dynasty are restored along with the Xiangjinong Lane Folk Houses in Ming Dynasty, one of the key cultural relic protection units.

There were traces of ceramic cultures of the five hundred years from the Five Dynasties to Ming Dynasty in the Ruins Protectorate in Hutian Kiln, including Liujia cove, North-South stone forwarding dock, snakehead ridge, Pipa Hill, etc.

As one of the typical cultural relic protection units selected since last 80s, Mt Maple Ceramic Culture Expo Area preserved the customized remains of ancient residents and the porcelain constructions.

And in Sanlv Temple Historical Reservation, ceramic cultural remains such as Sanlv Temple, Ming and Qing Dynasty Street, the Ancient Wharf, Yangfu Temple, Ming Residents in Liujia Lane can be found.

\subsection{The increasing ceramic creative cultural industry value of Jiangxi}

The incomparable ceramics made from the superb ceramics technology in Jiangxi enjoyed good reputation both in and out China, especially in recent years' development, during which Jiangxi ceramic creative cultural industries are on the rise.

Statistics show that population in Jingdezhen's ceramic creative cultural industries reached 50,000 in the first quarter of 2012, while the number of its idea factories and workshops was over 4,000 in 2013, including almost 10 national and provincial cultural industry demonstrating bases.

All of these revealed the broad development space of Jiangxi ceramic creative cultural industries values.

Chart.2 cultural values and ceramic creative cultural values in Jiangxi of 2011-2012

(Jingdezhen as an example)

\begin{tabular}{lll} 
Year & 2011 & 2012 \\
\hline
\end{tabular}

Cultural values

18.3 billion yuan

22 billion yuan

Creative cultural industry values

6.2 billion yuan

10 billion yuan

Ratio of creative cultural industries values

and cultural values

$33.8 \%$

$45.4 \%$

$20 \%$ increasing per year, in its ceramic cultural industry values.

In 2011 and 2012, the cultural values in Jingdezhen are respectively 18.3 and 22 billion yuan, while creative cultural industry values in the two years are 6.2 billion yuan and 10 billion yuan, ratio of the creative cultural industry values and cultural values rose from $33.8 \%$ to $45.4 \%$.

As is shown in Chart.2, Jingdezhen, main body of Jiangxi ceramics, has a rising tendency, an average

\subsection{The expanding industry scale of ceramic creative culture in Jingdezhen, Jiangxi}

With the development of social cultural industries, ceramic creative cultural industries in Jiangxi saw the good prospective of development and its growing scales.

On the one hand, cultural innovations of Jiangxi ceramics in the artistic modeling gained worldwide recognition, winning a place in the international market. At present, ceramics made in Jiangxi can be found every corner of the world, and the best well-known Franz has spread to over 5,000 countries. 
Apart from the widespread Franz, multiple cultural innovations have been applied to the daily ceramics. Jiangxi, successfully promoted nano ceramics, won a place in the new market.

On the other hand, starting from their own, Jiangxi constructed large-scale industry demonstration bases, providing broad developing space for the ceramics. To better integrate with advanced creative ideas, Jiangxi hold several cultural exchanges in2005. Inviting several famous culture innovation interlock to enter Jingdezhen, Jiangxi Province greatly promoted the development of the ceramic creative cultural industry.

Moreover, opening a window of multinational ceramics and technologies, Jiangxi gradually constructed a multiple characteristic cultural park that puts ceramic arts, catering and recreation together.

It could be said that the ceramic creative cultural industry of Jiangxi in recent years has formed a certain scale and it would grow bigger and bigger in the near future.

\section{Problems exit in Jiangxi’s ceramic creative cultural industry}

\subsection{Inadequate talents and insufficient motivation in creative cultural development}

Compared with China's economical developed eastern region, Jiangxi Province has no advantage in geographic position, while its underdeveloped economy and relatively low salaries add difficulties to attracting talents in the long run. Even with the world-famous honor of the porcelain city, Jingdezhen succeeded in cultivating professional talents while failed to retain the group who mostly went to other cities with highly developed economies.

From the current situation, several problems exit in ceramic creative cultural industry:

The first is the lack of professional talents of design oriented rather than technical ones, leading to the ceramic creative industry having no choice but seeking help from foreign professionals, losing the localization to a certain extent.

The second is the great disparities in the age distribution of talents. Gaps gradually become visible. Lack of professional talents has gradually become the key element impending Jiangxi's ceramic creative cultural industry. Weakened emphasize on the industry from the young added weight to the phenomenon.

The middle-aged formed the construction of talents in ceramic creative cultural industry a less proportion of the young which means the lack of successor among the middle aged and the young.

2.2 Loosened resource management and the lack of subject construction consciousness of cultural

\section{2 market}

Resource management is essential to the long-term development of a cultural industry, so does to the ceramic creative cultural industries in Jiangxi Province. Loosed resource management in Jiangxi ceramic creative cultural industries can be seen everywhere, especially in the following aspects.

One is that the subjects of the resource management failed to form a unit, which means that in the process of managing ceramic creative culture, government sectors and the public institutions fail to unit together, causing the imbalance in resource allocation and the lower status of the ceramics in the market.

The other is the incomplete management system. The ceramic creative cultural industry, compared with other industries, emphasized more on the stringency of the management, which is however, insufficient in today's Jiangxi. Some ceramic creative cultural industries in Jiangxi though had a loose management system and sometimes even no system, letting industries developing randomly and on their own.

This loosened management mode would surely affect the long-term development of Jiangxi's ceramic creative cultural industries. For one thing, loosing management put the whole industry in a state of 'out of order' that seriously affect the diversity of the market and hinder the formation of a normalized ceramic creative cultural market. 
For another, the looseness in management blurred the boundary between the managers and the market which means that the ceramic creative cultural industry lost the right developing orientation failing to find the real subject of management.

\subsection{Outdated ideology lacks innovative cultural brand consciousness}

Affected by geographic location and other social and economic factors, Jiangxi's ceramic creative cultural industries has a back warding ideology and singled products, failing to adopt to the social development.

It is near the bottom of the industrial chain in recent years under the traditional ideology and the primary stage of a labor-intensive industry relying mainly on the conventional human and natural resources. Meanwhile, the unawareness of brand consciousness, Jiangxi's ceramics purely depending on the traditional ceramic workshops leading to the lack of vitality essential to modern ceramics.

From an international perspective, Jiangxi's ceramics did not possess high end international vision, seriously restricted its cultural development space and greatly limited the overall developing scale.

Therefore, under the dual influence of outdated ideology and unawareness of brand consciousness, the ceramic creative cultural industry faced a series of problems in financing such as the limited scale of the government funds, difficulties in business credits and debts, inaccessible financing channels etc, making the ceramic creative cultural industry struggling in the mud.

\section{Optimization routes for the ceramic creative cultural industry in Jiangxi}

3.1 Innovating the personnel management mode and optimizing the human resource structure

Talent strategy must be the top priority of development for the ceramic creative cultural industry in Jiangxi or it will surely have bad effects to its long-term development.

First is to strengthen the talent cultivating in the local higher education by offering related specialties in colleges and universities. Certain adjustments to the talents cultivating mode with creative thinking is essential to meet the market demands.

Second is to choose excellent personnel to have studies and researches abroad under the mutual learning from both domestic and abroad to improve the overall level of Jiangxi ceramic creative cultural industry by cultivating high end talents with creative mind.

The third is to have timely optimization on human resource structure by improving the young proportion with rewarding system being set. Material incentives are necessary to attract more talents with rich salaries and rewards on their contributions.

It can be said that to subvert the traditional rigid human resource management in the ceramics, a thoroughly reform of letting the market to lead the optimal configuration of human resource is inevitable.

\subsection{Strengthening resource management and reforming ceramic creative industry}

The development of Jiangxi ceramic creative cultural industry calls for resource integration to have innovation.

The first thing is to pay attention to the resource integration of different elements of the cultural industry with structure adjusting being the main line to put the industry to the market. The complementary advantages of different industries can then realize with effective combination.

The second one is to emphasize on the excavation of the spiritual connotation of Jiangxi ceramic industry and the promotion of its cultural brand image, then integrating the connotation of ceramic creative industries with the products to improve the popularity.

The third is to transform the cultural brand into public welfare behaviour by timely and proper design to fuse the ceramic innovation with the products to the most.

Rome was not built in a day. Reforms on the ceramic creative industry need long-term research and practice. 


\subsection{Transforming ceramic cultural developing concept and formulating brand effect}

Striving to develop the creative culture of Jiangxi ceramics, it is essential to focus on transforming the ceramic cultural developing concept to forge brand effects with ideology reforming.

One thing is to upgrade the ideology with the times to transform the ceramic cultural thinking mode. Attention should be paid to the ceramic cultural propaganda, during which combing the culture elements together with emphasizes on products' artistry and creativity.

Another thing is that importance should be attached to the products environment by strengthening the propaganda on related ceramic industries to show the audience the real significance of the industry. Promotion and development from the public perspective can then achieve.

The last thing is paying attention to the optimization of the industries' dominant advantages to create the brand effect by powerful combination and collectivize running mode. Due to the decentralization of Jiangxi ceramic creative cultural industries, only by powerful combination can integrate the small workshops with cultural creativity to the whole creative cultural industrial chain, can improve the resource utilization to the most and can then promote the long-term development of the ceramic creative cultural industry.

\section{References}

[1] Gerritsen, Anne, McDowall, Stephen. Global China: Material Culture and Connections in World History [J]. Journal of World History . 2012 (1)

[2] Shu-Kam Chow,Kwok-Leung Chan. Reconstruction of Photorealistic 3D model of Ceramic Artefacts for Interactive Virtual Exhibition. Journal of Cultural Heritage. 2009

[3] Rona Boschma, Michael Fritseh. Creative Class and Regional Growth: Empirical Evidence from Seven European Countries. Economic Geography . 2009

[4] Bagwell S. Creative Clusters and City Growth. Creative Industries Journal. 2008

[5] Teresa Capepa. Kraak Porcelain: The Rise of Global Trade in the Late 16th and Early 17th Century. 2008 